\section{Biofilm resistant RPDs}

Solvay Dental 360 custom-developed Ultaire AKP specifically for the fabrication of RPDs. This high-performance polymer offers patients a metal-free alternative to traditional denture materials, which also demonstrates superior resistance to biofilm.

In a study that tracked the growth of biofilms for Candida albicans and Streptococcal species on Ultaire AKP, cobalt chrome and acetal resin - Ultaire AKP showed a significant improvement in performance against biofilms.

To book a Solvay Dental 360 Lunch and Learn or to find more information about Ultaire AKP, visit www. solvaydental360.com.

\title{
Convenient yet powerful
}

No doubt you've heard many patients guilty admit to rarely, if ever, flossing - despite being advised to again and again.

Thankfully there is a solution you can recommend to your patients that is convenient and effective - the Waterpik Water Flosser. It's simple to use and virtually effortless, yet it gets real results - removing up to $99.9 \%$ of biofilm from treated areas after just three seconds.

For more information on Waterpik products visit www.waterpik.co.uk or book a Waterpik Professional Lunch and Learn at www.waterpik. co.uk/professional/lunch-learn/

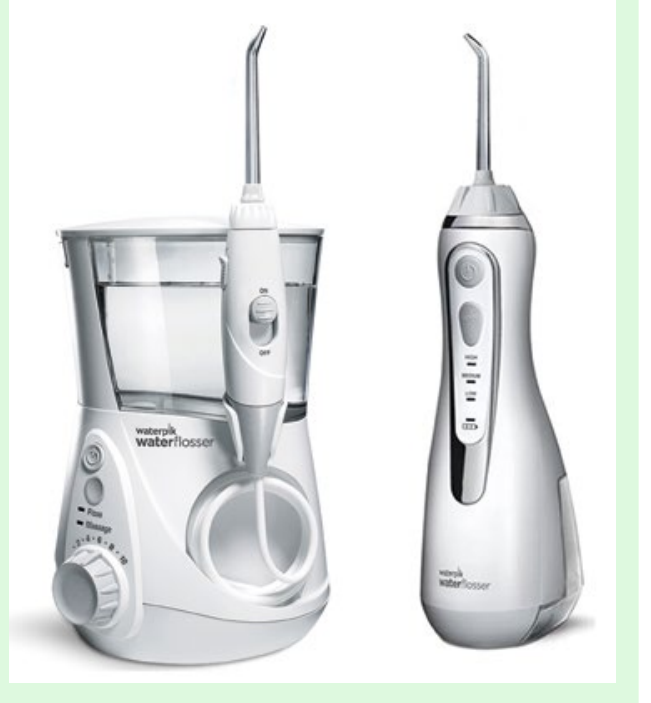

A simple but effective \section{solution}

We are all aware of the links between oral and systemic health. To help your patients lower the risks of health issues, manage periodontal concerns simply and effectively with Curasept ADS Perio from J\&S Davis.

The industry-leading solution offers targeted treatment of periodontal issues, providing all the bacteria fighting benefits of chlorhexidine while minimising the adverse side effects associated with similar products, such as discolouration and taste disturbance. Containing PVPVA and hyaluronic acid, it also protects the oral cavity from further bacterial colonisation and supports wound healing and repair.

For more information on the industry-leading products available from J\&S Davis, visit www.js-davis.co.uk, call 01438747344 or email jsdsales@ js-davis.co.uk.

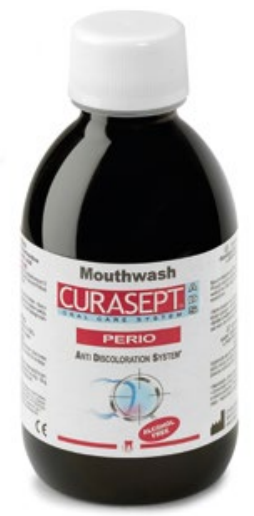

\section{First choice for first class disinfection}

Designed to help practices achieve first class disinfection safely, effectively and simply, the ThermoKlenz thermo washer disinfector dryer should be the first choice for any practice aiming for quality results.

Distributed by leading decontamination experts $\mathrm{W} \& \mathrm{H}$, the ThermoKlenz offers both effective cleaning through the automatic regulation of water temperature and detergent quantity, and drying through forced hot air that reduces residual moisture internally and externally. This ensures that instruments are $100 \%$ ready for sterilisation.

The ThermoKlenz is available with a KlenzSecure data logger, so that practices are able to keep electronic records of cleaning cycles - much more efficient than a paper trail.

To find out more visit www. wh.com/en_uk, call 01727874990 or email office.uk@wh.com.

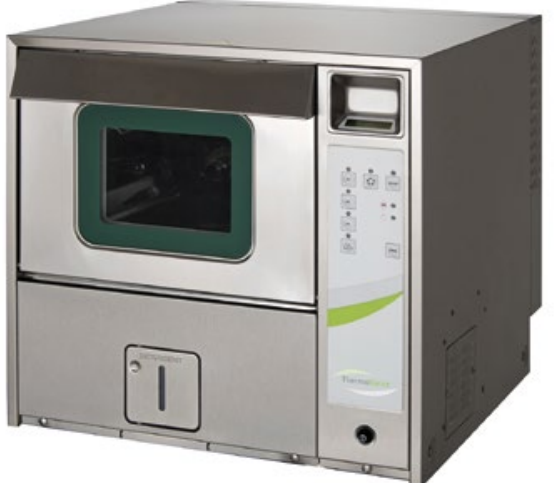

